Research Article

\title{
Construction and Application Analysis of Carbon Emission Influence Factor Model of Energy Consumption in Mining Industry
}

\author{
Lili Wei $\mathbb{D}^{1,2}$ Xiwen Feng $\mathbb{D}^{1},{ }^{1}$ and Guangyu Jia ${ }^{2}$ \\ ${ }^{1}$ College of Energy and Mining Engineering, Shandong University of Science and Technology, the Ministry of Mine Disaster \\ Prevention and Control Jointly Built the Cultivation Base of the State Key Laboratory, \\ National Demonstration Center for Experimental Mining Engineering Education, Qingdao 266590, China \\ ${ }^{2}$ School of Business, Shandong Jianzhu University, Jinan, China \\ Correspondence should be addressed to Xiwen Feng; fxw6380@163.com
}

Received 18 October 2021; Accepted 6 December 2021; Published 29 December 2021

Academic Editor: Qian Chen

Copyright $(92021$ Lili Wei et al. This is an open access article distributed under the Creative Commons Attribution License, which permits unrestricted use, distribution, and reproduction in any medium, provided the original work is properly cited.

\begin{abstract}
With the proposal of China's "double carbon goal," as a high energy-consuming industry, it is urgent for the mining industry to adopt a low-carbon development strategy. Therefore, in order to better provide reasonable suggestions and references for the lowcarbon development of mining industry, referring to the methods and parameters of the 2006 IPCC National Greenhouse Gas Inventory Guidelines and China's Provincial Greenhouse Gas Inventory Preparation Guidelines (Trial), a carbon emission estimation model is established to estimate the carbon emission of energy consumption of China's mining industry from 2000 to 2020. Then, using the extended Kaya identity, the influencing factors of carbon emission in mining industry are decomposed into energy carbon emission intensity, energy structure, energy intensity, industrial structure, and output value. On this basis, an LMDI model is constructed to analyze the impact of five factors on carbon emission from mining industry. The research shows that the carbon emission and carbon emission intensity of energy consumption in China's mining industry first rise and then fall and then rise slightly. The carbon emission intensity in recent three years is about 2 tons/ 10000 yuan. The increase in output value is the main factor to increase carbon emission. The reduction in energy intensity is the initiative of carbon emission reduction. The current energy structure of mining industry is not conducive to carbon emission reduction.
\end{abstract}

\section{Introduction and Literature Review}

China is not only the country with the largest energy production and consumption in the world, but also the country with the largest carbon emissions [1]. Since 2006, China has been the world's largest carbon emitter, with a total carbon emission of 9.9 billion tons in 2020 [2]. In September 2020, China made a solemn commitment to the world and will strive to achieve carbon peak by 2030 and carbon neutralization by 2060 [3]. This has attracted widespread attention all over the world and further accelerated the pace of global carbon emission reduction. After China put forward the goals of "carbon peak" and "carbon neutralization," it puts forward higher requirements for China's mining carbon emission reduction and low- carbon development [4]. According to China's historical statistics, in terms of average energy consumption intensity, nonmetallic ore mining and processing industry, ferrous metal ore mining and processing industry, coal mining and processing industry, nonferrous metal ore mining and processing industry, and petroleum and gas mining industry are all high energy-consuming industries, ranking $2 \mathrm{nd}$, 3rd, 7th, 11th, and 12th among 38 industrial subindustries, respectively [5]. As a high energy-consuming industry, it is of great significance to study the carbon emissions of China's mining energy consumption and the effects of its influencing factors for the green transformation and low-carbon development of mining industry.

The calculation of carbon emissions from energy consumption and its influencing factors are hot issues in recent 
years [6]. At present, the carbon emission estimation method basically adopts the method, calculation formula, and basic parameters of the 2006 IPCC National Greenhouse Gas Inventory Guidelines (IPCC Guidelines for short) and gives the specific estimation method in combination with the differences between countries and regions and different research objects [7]. The structural decomposition method or exponential decomposition method is mainly used to analyze the influencing factors of carbon emission [8]. Yoichi Kaya, a Japanese scholar, put forward the famous Kaya identity at an IPCC seminar, which decomposes carbon emission into the product of five factors: energy carbon emission intensity, energy structure, energy efficiency, per capita GDP, and population size, which well explains the influencing factors of carbon emission change and has been widely recognized [9]. Since then, many scholars have carried out a lot of research on the influencing factors of carbon emissions based on Kaya identity [10]. Ang et al. [11] compared the decomposition effects of various methods and found that the logarithmic mean Divisia index method can decompose multiple factors without residual [12]. Since then, this method has been widely used in the field of factor decomposition [13].

Different scholars have different influencing factors on carbon emissions in different regions [14]. Guo Chaoxian [15] believes that the expansion of economic scale is the main reason for the rapid growth of China's carbon emissions, and the reduction in energy consumption intensity makes the greatest contribution to emission reduction. Xie Shouhong et al. $[16,17]$ have shown that technology has a significant effect on emission reduction, while the structure has a small effect on emission reduction [18]. The research on industrial carbon emissions is mainly concentrated in agriculture [19], chemical industry [20], construction [21], transportation [22], tourism [23], etc. By analyzing the relevant literature, it is found that the research on the influencing factors of carbon emission of mining energy consumption is less and not in-depth. Most studies on the types of energy consumption only consider coal, crude oil, and natural gas [24].

To more comprehensively reflect the carbon emission of mining industry, this study considers not only 19 kinds of primary energy, but also 2 kinds of secondary energy. This avoids only considering the direct carbon emissions brought by energy consumption, while ignoring the indirect carbon emissions brought by secondary energy consumption. Fully considering the particularity of carbon emission calculation of secondary energy consumption, an estimation model of carbon emission of energy consumption in mining industry is constructed. At the same time, the particularity of the mining industry is fully considered, and the influencing factors are decomposed using the extended Kaya identity. On this basis, the LMDI model is constructed to analyze the action direction and influence the effect of the five factors on carbon emission, in order to provide an accurate reference for formulating the low-carbon development strategy of the mining industry.

\section{Research Methods and Data Sources}

2.1. Construction of the Carbon Emission Measurement Model. Referring to the IPCC Guidelines, the information indicating the occurrence degree of human activities is called activity data, and the coefficients used to quantify the emissions or removals caused by unit human activities are called emission factors [25].

Therefore, the basic idea of calculating carbon dioxide emissions is that carbon emissions are the product of activity data and emission factors.

2.1.1. Activity Data. In the calculation of energy consumption of carbon emissions, the activity data are the consumption of various energy sources. Based on the principle of no emphasis and no leakage, taking into account the characteristics of energy consumption in China's mining industry, this study selects 21 kinds of energy consumption to calculate carbon emissions. This includes 19 primary energy sources and 2 secondary energy sources.

2.1.2. Emission Factor. Emission factor refers to the $\mathrm{CO}_{2}$ emission generated by consuming unit energy, which actually refers to $\mathrm{CO}_{2}$ emission factor here. In order to compare the consumption of different kinds of energy, this study uses standard coal equivalent for all kinds of energy units. Referring to the IPCC Guidelines, $\mathrm{CO}_{2}$ emission factors have little to do with combustion technology. Assuming that the carbon oxidation rate in energy combustion is $100 \%, \mathrm{CO}_{2}$ emission factors mainly depend on the type of energy, that is, the carbon content of energy and the average low calorific value of energy. The low calorific value of standard coal adopted in China is $29307 \mathrm{~kJ}$ ( $7000 \mathrm{kcal}$ ) per kilogram of standard coal, i.e., $0.029307 \mathrm{TJ} / t$. Since the secondary energy consumption does not directly emit carbon dioxide, the outsourcing method is adopted to calculate the carbon emission. In this study, the secondary energy includes heat and electricity. The carbon dioxide emission of purchased heat and electricity is calculated using the emission factor of enterprise accounting carbon emission specified in China's carbon trading market. The emission factor of purchased heat is $0.11 \mathrm{tCO}_{2} / \mathrm{GJ}$ and the emission factor of purchased power grid is $0.6101 \mathrm{tCO}_{2} / \mathrm{MWh}$ [26], as shown in Table 1 .

Considering the difference between primary energy and secondary energy in calculating carbon emissions, this study calculates the carbon emissions of primary energy consumption and secondary energy consumption separately and finally adds them together. The sum is the total carbon emissions of energy consumption, which is calculated using formula (1); formula (2) is used to calculate the carbon emission of primary energy consumption alone, formula (3) is used to calculate the thermal carbon emission alone, and formula (4) is used to calculate the carbon emission of electricity consumption alone. The calculation formulas are as follows:

$$
T_{\mathrm{CO} 2}=T_{\mathrm{CO} 2}^{1}+T_{\mathrm{CO} 2 \mathrm{R}}+T_{\mathrm{CO} 2 \mathrm{D}}
$$


TABLE 1: Default carbon content and carbon emission factors.

\begin{tabular}{lcc}
\hline Code & Energy sources & Carbon content per unit calorific value (tC/TJ) \\
\hline 1 & Raw coal & $26.37^{\mathrm{a}}$ \\
2 & Cleaned coal & $25.41^{\mathrm{a}}$ \\
3 & Other washed coal & $25.41^{\mathrm{a}}$ \\
4 & Coke & $29.42^{\mathrm{a}}$ \\
5 & Coke oven gas & $13.58^{\mathrm{a}}$ \\
6 & Blast furnace gas & $70.80^{\mathrm{b}}$ \\
7 & Other gas & $12.20^{\mathrm{a}}$ \\
8 & Other coking products & $29.50^{\mathrm{a}}$ \\
9 & Crude oil & $20.10^{\mathrm{a}}$ \\
10 & Gasoline & $18.90^{\mathrm{a}}$ \\
11 & Kerosene & $19.60^{\mathrm{a}}$ \\
12 & Diesel oil & $20.20^{\mathrm{a}}$ \\
13 & Fuel oil & $21.10^{\mathrm{a}}$ \\
14 & Liquefied petroleum gas & $17.20^{\mathrm{a}}$ \\
15 & Refinery gas & $18.20^{\mathrm{a}}$ \\
16 & Naphtha & $20.00^{\mathrm{a}}$ \\
18 & Other petroleum products & $20.00^{\mathrm{a}}$ \\
21 & Natural gas & $15.32^{\mathrm{a}}$ \\
\hline
\end{tabular}

${ }^{\mathrm{a}}$ Tthe data source is the Provincial Greenhouse Gas Inventory Preparation Guidelines (Trial) [27]. ${ }^{\mathrm{b}}$ The data source is the 2006 IPCC National Greenhouse Gas Inventory Guidelines [25]. 'The data source is the Guidelines for Accounting Methods and Reporting of Greenhouse Gas Emissions of Enterprises [26].

where $T_{\mathrm{CO} 2}$ refers to the total $\mathrm{CO}_{2}$ emission caused by all energy consumption, and the unit is tons of carbon dioxide $\left(\mathrm{tCO}_{2}\right) ; \mathrm{T}^{1} \mathrm{CO} 2$ refers to the total $\mathrm{CO}_{2}$ emission caused by primary energy consumption, and the unit is $\mathrm{tCO}_{2} ; T_{\mathrm{CO} 2 \mathrm{R}}$ refers to the total $\mathrm{CO}_{2}$ emission caused by thermal energy consumption, in tons of carbon dioxide (tCO2); and $T_{\mathrm{CO} 2 \mathrm{D}}$ refers to the total $\mathrm{CO}_{2}$ emissions caused by electricity consumption, in tons of carbon dioxide $\left(\mathrm{tCO}_{2}\right)$. In this study, heat and electricity are regarded as secondary energy, and coal, petroleum, and natural gas are regarded as primary energy.

$$
\mathrm{T}_{\mathrm{CO}_{2}}^{1}=\sum_{\mathrm{k}} \sum_{\mathrm{j}} \mathrm{E}_{\mathrm{kj}} \times \mathrm{H} \times \mathrm{C}_{\mathrm{j}} \times \mathrm{O}_{\mathrm{kj}} \times \frac{44}{12},
$$

where $\mathrm{T}^{1}{ }_{\mathrm{CO} 2}$ refers to the total $\mathrm{CO}_{2}$ emission caused by primary energy consumption, and the unit is tons of carbon dioxide $\left(\mathrm{tCO}_{2}\right) ; \mathrm{E}_{\mathrm{kj}}$ refers to the consumption of the jth energy in sector $k$, in tons of standard coal (TCE); $C_{\mathrm{j}}$ refers to the carbon content per unit calorific value of the jth energy, in tc/TJ, as shown in Table $1 ; \mathrm{H}$ refers to the average low calorific value of unit standard coal, i.e., $0.029307 \mathrm{TJ} / t$; and $\mathrm{O}_{\mathrm{kj}}$ refers to the carbon oxidation rate of the $\mathrm{jth}$ energy in sector $k$. Here, the carbon oxidation rate of all energy in all sectors is $100 \%$ by default; 12 is the atomic weight of $\mathrm{C}$, and 44 is the molecular weight of $\mathrm{CO}_{2}$.

$$
\mathrm{T}_{\mathrm{CO} 2 \mathrm{R}}=\sum_{\mathrm{k}} \mathrm{E}_{\mathrm{kR}} \times \mathrm{O}_{\mathrm{k}} \times \mathrm{RF},
$$

where $T_{\mathrm{CO} 2 \mathrm{R}}$ refers to the total $\mathrm{CO}_{2}$ emission caused by thermal energy consumption, and the unit is tons of carbon dioxide $\left(\mathrm{tCO}_{2}\right) ; \mathrm{E}_{\mathrm{kR}}$ refers to the consumption of thermal energy in sector $k$, in tons of standard coal (tce); and RF refers to thermal emission factor of $0.11 \mathrm{tCO}_{2} / \mathrm{GJ}$, as shown in Table 1.

$$
\mathrm{T}_{\mathrm{CO} 2 \mathrm{D}}=\sum_{\mathrm{k}} \mathrm{E}_{\mathrm{kD}} \times \mathrm{DF}
$$

where $T_{\mathrm{CO} 2 \mathrm{D}}$ refers to the total $\mathrm{CO}_{2}$ emission caused by the use of electricity, and the unit is tons of carbon dioxide $\left(\mathrm{tCO}_{2}\right) ; \mathrm{E}_{\mathrm{kD}}$ refers to the consumption of electric energy in sector $k$, in megawatt hours (MWh); and DF refers to electricity $\mathrm{CO}_{2}$ emission factor of $0.6101 \mathrm{tCO}_{2} / \mathrm{MWh}$, as shown in Table 1.

\subsection{Constructing the Effect Model of Influencing Factors of Carbon Emission}

2.2.1. Introduction of the LMDI Method. The logarithmic mean Divisia index method (LMDI method for short) is a kind of exponential decomposition method. It was proposed by Ang in 1998 to solve the original residual value and zerovalue problems of exponential decomposition analysis method [11]. The LMDI method is based on the following functions:

$$
\begin{aligned}
& L(x, y)=\frac{(x-y)}{\ln (x / y)} \quad x>0, y>0, \\
& L(0,0)=0 .
\end{aligned}
$$

For any factorization, $C_{t}=X_{t} \times Y_{t}$, the associative function $L(x, y)$ has the following: 


$$
\begin{aligned}
& \triangleleft C_{X}=L\left(C_{t}, C_{0}\right) \operatorname{In}\left(\frac{X_{t}}{X_{0}}\right), \\
& \triangleleft C_{Y}=L\left(C_{t}, C_{0}\right) \ln \left(\frac{Y_{t}}{y_{0}}\right) .
\end{aligned}
$$

Here, $C$ represents the objective function, $X$ and $Y$ represent the influencing factors, $X_{\mathrm{t}}, Y_{\mathrm{t}}$, and $C_{\mathrm{t}}$, respectively, represent the values of $X, Y$, and $C$ in $t$ period (when $t=0$, it represents the value of base period), and $\Delta C_{X}$ and $\Delta C_{\mathrm{Y}}$, respectively, represent the change value of $\mathrm{C}$ under the action of $X$ and $\mathrm{Y}$ alone. By comparing $\Delta C_{\mathrm{X}}$ and $\Delta C_{\mathrm{Y}}$, the influence weight of $X$ and $\mathrm{Y}$ on $\mathrm{C}$ can be obtained.

\subsubsection{Construction of the LMDI Effect Analysis Model.} (1) Decomposition of Influencing Factors of Carbon Emission. The original Kaya identity decomposes the influencing factors of carbon emission into five factors: energy carbon emission intensity, energy structure, energy efficiency, per capita GDP, and population size. Considering the particularity of mining industry as a basic industry, this study decomposes the factors affecting the carbon emission of mining energy consumption using the extended Kaya identity, which is expressed by the following formula:

$$
\mathrm{C}=\sum_{\mathrm{k}} \sum_{\mathrm{j}} \frac{\mathrm{C}_{\mathrm{kj}}}{\mathrm{E}_{\mathrm{kj}}} \times \frac{\mathrm{E}_{\mathrm{kj}}}{\mathrm{E}_{\mathrm{k}}} \times \frac{\mathrm{E}_{\mathrm{k}}}{\mathrm{GDP}_{\mathrm{k}}} \times \frac{\mathrm{GDP}_{\mathrm{k}}}{\mathrm{GDP}} \times \mathrm{GDP},
$$

where $C$ is the carbon dioxide emission of total energy consumption, $C_{\mathrm{kj}}$ is the carbon dioxide emission of class $j$ energy consumption in industry $k, \mathrm{E}_{\mathrm{kj}}$ is the class $j$ energy consumption in industry $k, E_{\mathrm{k}}$ is the energy consumption of industry $k, \mathrm{GDP}_{\mathrm{k}}$ is the output value of industry $k$, and GDP is the total output value of all industries.

Also, the following are defined:

$T_{\mathrm{kj}}=\mathrm{C}_{\mathrm{kj}} / \mathrm{E}_{\mathrm{kj}}$ is the carbon emission intensity of energy, indicating the $\mathrm{CO}_{2}$ emission of $j$ type energy consumed by $k$ industry, which is related to energy production technology.

$\mathrm{S}_{\mathrm{kj}}=\mathrm{E}_{\mathrm{kj}} / E_{\mathrm{k}}$ is the energy structure, indicating the proportion of $j$ type energy consumption in total energy consumption in $k$ industry.

$V_{\mathrm{k}}=E_{\mathrm{k}} / \mathrm{GDP}_{\mathrm{k}}$ is the energy intensity, indicating the energy consumption per unit output value of $k$ industry.

$M_{\mathrm{k}}=\mathrm{GDP}_{\mathrm{k}} / \mathrm{GDP}$ is the industrial structure, indicating the proportion of $k$ industry output value in the total output value.

$G=$ GDP is the total output value, which means the total output value of all industries.

(2) Construction of the LMDI Analysis Model. The LMDI method is used to analyze the change in carbon emission of energy consumption caused by the separate action of the above five factors. Assuming that the total carbon emission in $\mathrm{t}-1$ and $t$ period is $\mathrm{Ct}-1$ and $\mathrm{Ct}$, respectively, the comprehensive benefit $\Delta \mathrm{C}$ of carbon emission is expressed as follows:

$$
\Delta C=\Delta C^{t}-\Delta C^{t-1}=\Delta C_{T}+\Delta C_{s}+\Delta C_{V}+\Delta C_{M}+\Delta C_{G}
$$

Here, $\Delta C_{\mathrm{T}}, \Delta C_{\mathrm{S}}, \Delta C_{\mathrm{V}}, \Delta C_{\mathrm{M}}$, and $\Delta C_{\mathrm{G}}$, respectively, represent the effects of $\mathrm{T}_{\mathrm{kj}}, S_{\mathrm{k}}, V_{\mathrm{k}}, M_{\mathrm{k}}$, and $\mathrm{G}$ on carbon emission.

According to the LMDI decomposition principle, the effects of five factors on carbon emission $\Delta C_{\mathrm{T}}, \Delta C_{\mathrm{S}}, \Delta C_{\mathrm{V}}$, $\Delta C_{\mathrm{M}}$, and $\Delta C_{\mathrm{G}}$ can be expressed, respectively:

$$
\begin{aligned}
& \Delta \mathrm{CT}=\sum_{\mathrm{k}} \sum_{\mathrm{j}} \mathrm{L}\left(\mathrm{C}_{\mathrm{kj}}^{\mathrm{t}}, \mathrm{C}_{\mathrm{kj}}^{\mathrm{t}-1}\right) \ln \left(\frac{\mathrm{T}_{\mathrm{kj}}^{\mathrm{t}}}{\mathrm{T}_{\mathrm{kj}}^{\mathrm{t}-1}}\right), \\
& \Delta \mathrm{CS}=\sum_{\mathrm{k}} \sum_{\mathrm{j}} \mathrm{L}\left(\mathrm{C}_{\mathrm{kj}}^{\mathrm{t}}, \mathrm{C}_{\mathrm{kj}}^{\mathrm{t}-1}\right) \ln \left(\frac{S_{k j}^{t}}{S_{k j}^{t-1}}\right), \\
& \Delta \mathrm{CV}=\sum_{\mathrm{k}} \sum_{\mathrm{j}} \mathrm{L}\left(\mathrm{C}_{\mathrm{kj}}^{\mathrm{t}}, \mathrm{C}_{\mathrm{kj}}^{\mathrm{t}-1}\right) \ln \left(\frac{V_{k j}^{t}}{V_{k j}^{t-1}}\right), \\
& \Delta \mathrm{CM}=\sum_{\mathrm{k}} \sum_{\mathrm{j}} \mathrm{L}\left(\mathrm{C}_{\mathrm{kj}}^{\mathrm{t}}, \mathrm{C}_{\mathrm{kj}}^{\mathrm{t}-1}\right) \ln \left(\frac{M_{k j}^{t}}{M_{k j}^{t-1}}\right), \\
& \Delta \mathrm{CG}=\sum_{\mathrm{k}} \sum_{\mathrm{j}} \mathrm{L}\left(\mathrm{C}_{\mathrm{kj}}^{\mathrm{t}}, \mathrm{C}_{\mathrm{kj}}^{\mathrm{t}-1}\right) \ln \left(\frac{G_{k j}^{t}}{G_{k j}^{t-1}}\right) .
\end{aligned}
$$

\subsection{Data Source and Data Processing}

2.3.1. Research Object and Data Scope. The research period is $2000-2020$, a total of 21 years.

The research industries are five major sectors in China's mining industry: mining and washing of coal, extraction of petroleum and natural gas, mining and processing of ferrous metal ores, mining and processing of nonferrous metal ores, and mining and processing of nonmetal ores. The reason is that the output value data of " mining of other ores" began to be counted in 2003, the output value accounted for less than $0.1 \%$, and the terminal energy consumption accounted for less than $2 \%$, while the "professional and support activities for mining" appeared only in 2012, and the output value accounted for a very low proportion.

Definition of energy types studied: 21 kinds of energy are considered when calculating carbon emissions. There are 28 kinds of energy in the data of terminal energy consumption after 2010 in the China Energy Statistics Yearbook, but the energy consumption of petroleum coke, paraffin, solvent oil, petroleum asphalt, and other energy sources is very small and can be ignored. At the same time, except coke oven gas and blast furnace gas, the remaining gas is classified as other gas, as shown in Table 1. In the LMDI analysis method, energy types are divided into four categories: coal, petroleum, natural gas, and secondary energy. Among them, coal includes raw coal, cleaned coal, other coal washing, coke, coke oven gas, blast furnace gas, other gas, and other coking products. Petroleum includes crude oil, gasoline, diesel oil, 
kerosene, fuel oil, liquefied petroleum gas, refinery dry gas, naphtha, and other petroleum products. Natural gas includes natural gas and liquefied natural gas. Secondary energy includes electricity and heat.

2.3.2. Data Source. The industrial output value comes from the main business income of industrial enterprises above designated size by industry in the China Statistical Yearbook [28]. The reason is that the statistics of industrial output value in the whole time period is discontinuous, and because there is a certain proportional relationship between the main business income and industrial output value, the main business income is adopted for the consistency of statistical data.

The energy consumption values are all from the end energy consumption of industries in the China Energy Statistical Yearbook [29]. To avoid repeated calculation and unclear conversion coefficient of standard coal, the standard coal equivalent in the statistical yearbook is adopted.

2.3.3. Data Processing. In order to make the output value of different years comparable, the industry output value is subject to fixed base treatment, and the base period is based on the ex-factory price index of industrial producers of various industries in 2000.

In the analysis process using the LMDI method, the industry is divided into five industries: mining and washing of coal, extraction of petroleum and natural gas, mining and processing of ferrous metal ores, mining and processing of nonferrous metal ores, and mining and processing of nonmetal ores. Energy types are divided into four categories: coal, petroleum, natural gas, and secondary energy.

As mentioned above, according to the LMDI decomposition principle, the effects of the five factors on carbon emission $\Delta C_{\mathrm{T}}, \Delta C_{\mathrm{S}}, \Delta C_{\mathrm{V}}, \Delta C_{\mathrm{M}}$, and $\Delta C_{\mathrm{G}}$ are specifically expressed as follows:

$$
\begin{array}{r}
\Delta \mathrm{CT}=\sum_{k=1}^{5} \sum_{j=1}^{4} L\left(C_{k j}^{t}, C_{k j}^{t-1}\right) \ln \left(\frac{T_{k j}^{t}}{T_{k j}^{t-1}}\right), \\
\Delta \mathrm{CS}=\sum_{k=1}^{5} \sum_{j=1}^{4} L\left(C_{k j}^{t}, C_{k j}^{t-1}\right) \ln \left(\frac{S_{k j}^{t}}{S_{k j}^{t-1}}\right), \\
\Delta \mathrm{CV}=\sum_{k=1}^{5} \sum_{j=1}^{4} L\left(C_{k j}^{t}, C_{k j}^{t-1}\right) \ln \left(\frac{V_{k j}^{t}}{V_{k j}^{t-1}}\right), \\
\Delta \mathrm{CM}=\sum_{k=1}^{5} \sum_{j=1}^{4} L\left(C_{k j}^{t}, C_{k j}^{t-1}\right) \ln \left(\frac{M_{k j}^{t}}{M_{k j}^{t-1}}\right), \\
\triangle \mathrm{CG}=\sum_{k=1}^{5} \sum_{j=1}^{4} L\left(C_{k j}^{t}, C_{k j}^{t-1}\right) \ln \left(\frac{G_{k j}^{t}}{G_{k j}^{t-1}}\right) .
\end{array}
$$

\section{Analysis of Calculation Results of Carbon Emissions from Energy Consumption of China's Mining Industry}

According to the end energy consumption of industrial subindustries in the China Energy Statistical Yearbook from 2000 to 2020 , combined with the carbon emission factor in Table 1, the carbon emission of mining energy consumption is calculated using formulas (1)-(4). The calculation results of total carbon emission are shown in Table 1.

From 2000 to 2016, the total carbon emission of energy consumption in China's mining industry increased first and then decreased, as shown in Figure 1. From 24.78089 million tons of carbon dioxide in 2000 to 24.78089 million tons in 2013, the emission in 2013 became the highest in history. It decreased rapidly to 37.17986 million tons in 2014 , a decrease of $15.72 \%$ compared with 2013, as shown in Table 2. The whole change trend of carbon emission is consistent with the change in energy consumption. Compared with the change in carbon emission, the change in output value lags behind. The highest point of output value was 2659354 billion yuan in 2014, but it only decreased slightly in 2015 . This may be because this study uses the main business income to replace the industrial output value. Because the market demand has not changed, the enterprise inventory makes up for the reduction in output value. In 2016, the carbon emission was 334.2 million tons, which became the lowest in history. After that, the carbon emission fluctuated slightly and rebounded to 352.1794 million tons by 2020 , as shown in Figure 1.

In terms of the industrial structure of the mining industry, mining and washing of coal is the largest contributor to the carbon emission of the mining industry. Since 2003, its carbon emission has accounted for more than $40 \%$. The second is the oil and gas exploitation industry, but the proportion fluctuates greatly. It first decreased and then increased slightly. Its proportion reached $45.37 \%$ in 2000 and decreased to $27.57 \%$ in 2020 . The carbon emission of nonmetallic industry is the third, that of ferrous metal industry is the fourth, and that of nonferrous metal industry is the last, as shown in Figure 2.

The carbon emission intensity of China's mining industry generally showed a downward trend from 2000 to 2020, as shown in Figure 3. From 4.98 tons/10000 yuan in 2000 to 1.34 tons/10000 yuan in 2016, the carbon emission intensity in 2016 was the lowest in history. Compared with 2000, 2016 decreased by $73.1 \%$, and the carbon emission intensity increased slightly after 2017. It is 2.18 tons $/ 10000$ yuan in 2020 , a decrease of $41.56 \%$ compared with 3.73 tons/10000 yuan in 2005. The National Climate Change Plan (2014-2020) [30] puts forward the goal of reducing carbon emission intensity by $40 \%-45 \%$ in 2020 compared with 2005. Compared with the national target, the decline of carbon emission intensity of mining industry is still too small. From the perspective of each subindustry, the coal industry has a relatively rapid decline in carbon emission 


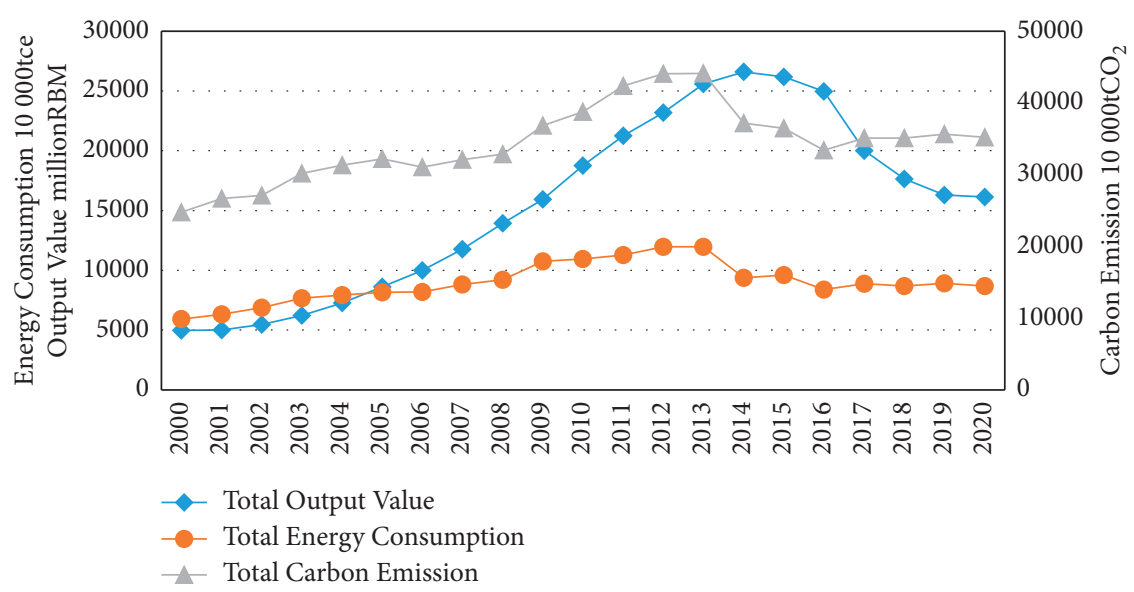

FIGURE 1: Total output value, total energy consumption, and total carbon emission of China's mining industry from 2000 to 2020.

TABLE 2: Total carbon emissions of China's mining industry from 2000 to 2020.

\begin{tabular}{lc}
\hline Year & Emission $\left(10^{4}\right.$ t) \\
\hline 2000 & 24780.89 \\
2001 & 26675.79 \\
2002 & 27143.31 \\
2003 & 30176.47 \\
2004 & 31326.72 \\
2005 & 32197.38 \\
2006 & 31047.9 \\
2007 & 32111.72 \\
2008 & 32870.6 \\
2009 & 36881.97 \\
2010 & 38742.34 \\
2011 & 42359.86 \\
2012 & 44099.26 \\
2013 & 44112.95 \\
2014 & 37179.86 \\
2015 & 36451.58 \\
2016 & 33420 \\
2017 & 35117.64 \\
2018 & 35093.41 \\
2019 & 35670.86 \\
2020 & 35217.95 \\
\hline
\end{tabular}

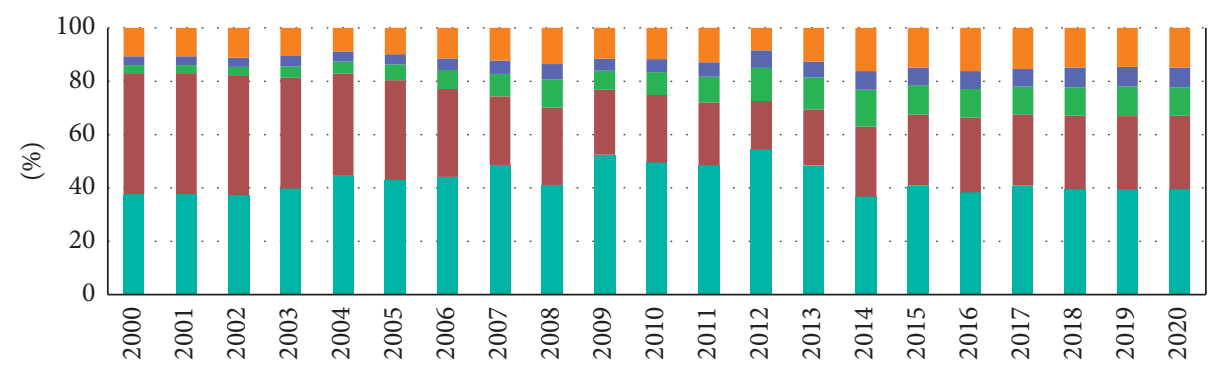

- Mining and Processing of Nonmetal Ores

- Mining and Processing of Non-Ferrous Metal Ores

- Mining and Processing of Ferrous Metal Ores

- Extraction of Petroleum and Natural Gas

- Mining and Washing of Coal

Figure 2: Analysis of the proportion of carbon emissions of various industries from 2000 to 2020. 


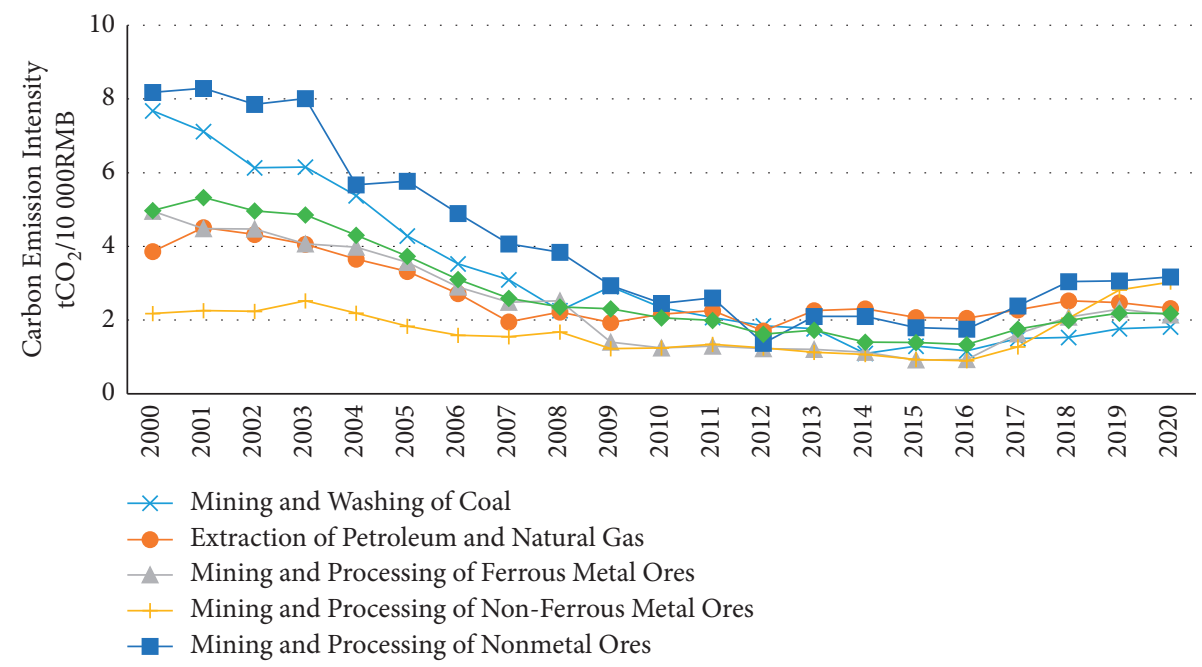

Figure 3: Carbon emission intensity of output value of various industries from 2000 to 2020.

intensity, which decreased from 768 tons/10000 yuan in 2000 to 109 tons/10000 yuan in 2014 and then rebounded to 1.8 tons/10000 yuan in 2020 . The nonmetallic industry decreased from 8.18 tons/10000 yuan in 2000 to 1.37 tons/10000 yuan in 2012 and then increased to 3.17 tons/10000 yuan in 2020 , becoming the industry with the highest carbon emission intensity in the mining industry. The carbon emission intensity of the nonferrous metal industry increased sharply after a slight decrease in the whole process and finally increased instead of decreasing. The change in carbon emission intensity of the petroleum and natural gas industry is the smallest, which was 3.86 tons/10000 yuan in 2000 and 2.32 tons/10000 yuan in 2020. In comparison, the petroleum and natural gas industry is the industry with the greatest pressure on emission reduction.

In this study, heat and electricity are regarded as secondary energy, and coal, petroleum, and natural gas are regarded as primary energy. According to the analysis of Figure 3 , the carbon emission of secondary energy continues to increase. By 2014, the carbon emission of secondary energy exceeds that of primary energy, and the difference is becoming larger and larger. According to the statistical data of energy consumption, the proportion of secondary energy continues to increase, reaching $33.93 \%$ in 2014 , exceeding the proportion of coal energy. By 2020, the proportion of secondary energy will be $39.28 \%$. The research data show that the carbon emission intensity of secondary energy is higher than that of primary energy, as shown in Figure 4.

\section{Decomposition Analysis of Carbon Emission Factors of Energy Consumption in China's Mining Industry}

This study uses Stata Software to calculate the carbon emission effects of five factors according to formulas (14)-(18) in the LMDI analysis model. According to the model, the annual effect of each factor is calculated first and then the cumulative effect of each factor every year is calculated.
4.1. Factor Annual Effect Analysis. Using the LMDI method, the change in carbon emission $\triangle \mathrm{C}$ in the current year is decomposed into the influence effects of five factors by taking the previous year as the base period. $\Delta C_{\mathrm{T}}$ represents the energy carbon emission intensity, $\Delta C_{\mathrm{S}}$ represents the energy structure, $\Delta C_{\mathrm{V}}$ represents the energy intensity, $\Delta C_{\mathrm{M}}$ represents the industrial structure, and $\Delta C_{\mathrm{G}}$ represents the total output value. The calculation results are shown in Table 3.

From the annual change in total carbon emissions, annual carbon emissions increased from 2001 to 2013, except in 2006. In 2009, the highest value was increased by 40113700 tons. From 2014, carbon emissions in other years were reduced except in 2017 and 2019, as shown in Table 3. The biggest impact on carbon emissions is the output value effect and energy intensity effect. The output value effect is the driving force to increase carbon emissions. It has been a positive effect from 2002 to 2014 , and the effect value has been very stable, reaching the highest value of 61.44057 million tons in 2010; the output value effect was negative from 2015 to 2020, and the highest negative effect in 2017 was -76.08057 million tons. The data show that the reduction in carbon emissions in recent five years is mainly due to the reduction in output value.

Energy intensity is the main factor to promote carbon emission reduction. From 2002 to 2016, the energy intensity effect was basically negative and stable. However, the energy intensity effect in 2017-2019 is positive, and the highest value of positive effect in 2017 is 86.9516 million tons, which reflects that the energy consumption per unit output value of mining industry has not decreased but increased in recent years. At the same time, the energy carbon emission intensity factor also has a positive effect on carbon emission reduction. The energy carbon emission intensity effect has been negative from 2001 to 2009 , and the positive and negative values fluctuated frequently after 2010 . The energy structure effect was basically negative before 2009 and fluctuated greatly in the later period, as shown in Figure 5. The industrial structure effect shows phased changes. The 


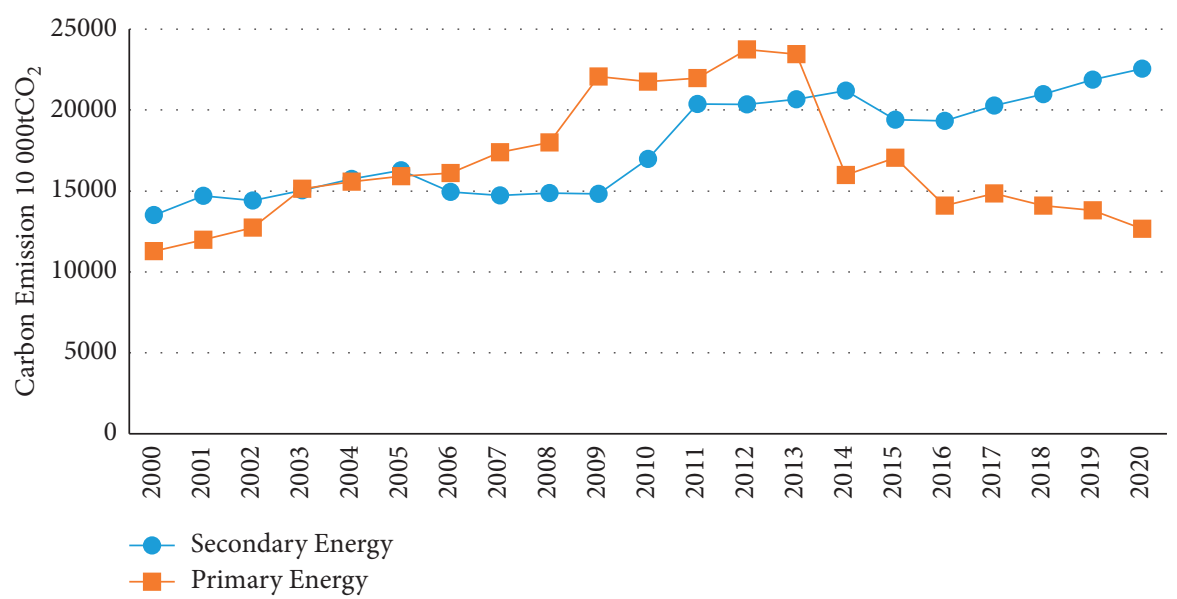

FIgURE 4: Carbon emissions of primary and secondary energy of China's mining industry from 2000 to 2020.

TABLE 3: Annual effects of various factors of carbon emission from 2001 to $2020\left(10^{4} \mathrm{t}\right)$.

\begin{tabular}{|c|c|c|c|c|c|c|}
\hline Year & $\Delta \mathrm{C}$ & $\Delta_{\mathrm{CT}}$ & $\Delta C_{\mathrm{S}}$ & $\Delta C_{\mathrm{V}}$ & $\Delta C_{\mathrm{M}}$ & $\Delta C_{\mathrm{G}}$ \\
\hline 2001 & 1894.90 & -53.50 & 214.56 & 1360.03 & 1143.80 & -1839.73 \\
\hline 2002 & 467.52 & -1485.03 & -338.53 & -351.64 & 274.25 & 2368.47 \\
\hline 2003 & 3033.14 & 522.51 & -430.01 & -735.07 & -8.41 & 3684.12 \\
\hline 2004 & 1150.27 & -290.43 & 1141.88 & -5135.43 & 637.92 & 4796.33 \\
\hline 2005 & 870.67 & -168.64 & -17.69 & -4463.01 & 95.64 & 5424.37 \\
\hline 2006 & -1149.48 & -161.81 & -1261.55 & -4622.51 & 269.40 & 4626.99 \\
\hline 2007 & 1063.82 & -854.29 & -364.84 & v3239.87 & 316.64 & 5206.19 \\
\hline 2008 & 758.88 & -724.83 & -995.66 & -3233.41 & 261.42 & 5451.35 \\
\hline 2009 & 4011.37 & -324.21 & 57.94 & -374.57 & -12.11 & 4664.32 \\
\hline 2010 & 1860.37 & 419.86 & 641.49 & -5340.95 & -4.09 & 6144.06 \\
\hline 2011 & 3617.52 & 1088.08 & 1109.99 & -3545.36 & -72.53 & 5037.34 \\
\hline 2012 & 1739.41 & -1141.27 & -575.45 & 320.29 & -586.63 & 3722.46 \\
\hline 2013 & 13.69 & -342.79 & 606.51 & -4352.68 & -233.19 & 4335.83 \\
\hline 2014 & -6933.09 & 787.18 & 1322.06 & -10605.97 & 3.31 & 1560.33 \\
\hline 2015 & -728.29 & -688.22 & -437.68 & 348.47 & 625.55 & -576.41 \\
\hline 2016 & -3031.58 & 682.62 & 958.66 & -3329.85 & 296.32 & -1639.33 \\
\hline 2017 & 1697.64 & 42.92 & 109.99 & 8695.16 & 457.62 & -7608.06 \\
\hline 2018 & -24.23 & 615.56 & -339.89 & 4371.51 & -294.52 & -4376.88 \\
\hline 2019 & 577.45 & -474.16 & 248.95 & 3201.67 & 390.43 & -2789.44 \\
\hline 2020 & -452.91 & 0.00 & 468.34 & -617.55 & 67.40 & -371.10 \\
\hline
\end{tabular}

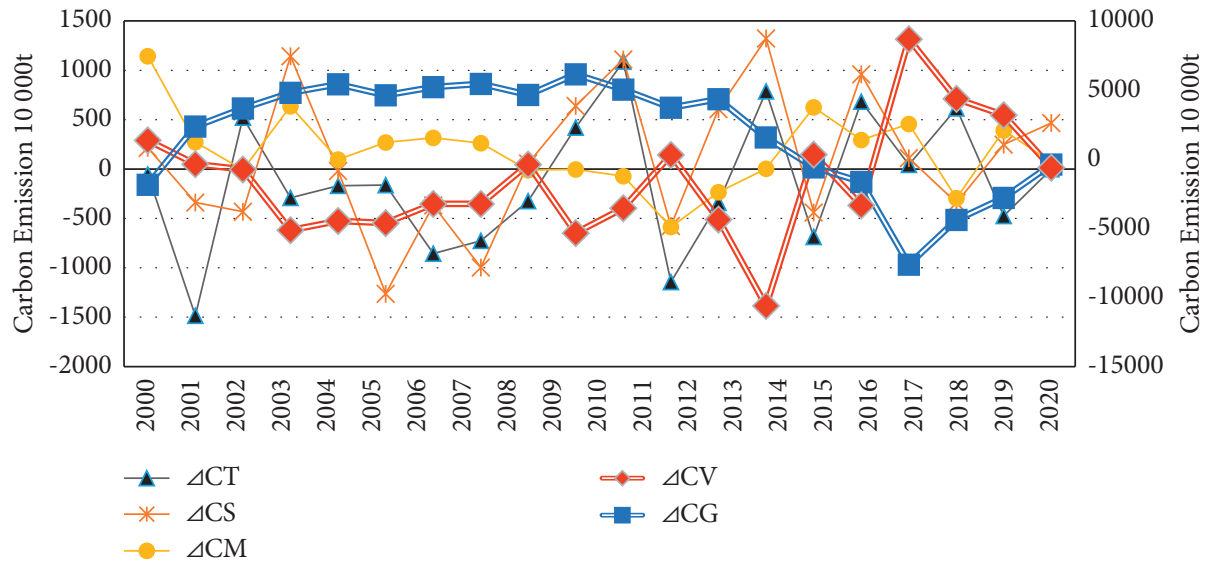

FIGURE 5: Annual effects of various factors on carbon emission from 2001 to 2020. Note: due to the great difference in the effect values of various factors, in order to intuitively reflect the change in the effect of various factors, the right longitudinal axis coordinates are used for $\Delta C_{\mathrm{V}}$ and $\Delta C_{\mathrm{G}}$ in Figure 5, and the left longitudinal axis coordinates are used for the other factors. 
industrial structure effect was positive from 2001 to 2008, negative from 2009 to $2013,-2945200$ tons in 2018, and positive in other years, as shown in Table 3.

4.2. Factor Cumulative Effect Analysis. Taking 2000 as the base period, the effects of various factors each year are accumulated to calculate the cumulative effects of carbon emission factors of energy consumption of China's mining industry from 2001 to 2020, as shown in Table 4. From 2001 to 2020, the cumulative value of carbon emissions increased first, then decreased, and finally reached a stable stage, as shown in Figure 6. The cumulative carbon emission in 2013 was 193.3206 million tons, which became the highest value in history, and the cumulative value decreased to 104.37006 million tons in 2020, indicating that the emission reduction effect of the mining industry in recent ten years is relatively significant.

4.2.1. Analysis of Output Value Effect. From 2001 to 2020, the cumulative value of output value effect increased first and then decreased, as shown in Figure 6. In 2014, the cumulative effect of output value was 55.18242 million tons, which became the highest value. Because the annual effect of output value in 2015-2020 was negative, the cumulative effect of output value in 2020 decreased to 37.82121 million tons, as shown in Table 4 . The analysis data show that the increase in output value is the largest contributor to the increase in carbon emissions. The main measure for China's mining industry to reduce carbon emissions after 2015 is to reduce output value.

4.2.2. Analysis of Energy Intensity Effect. It can be seen from Figure 6 that the biggest contributor to the promotion of carbon emission reduction by the mining industry is energy intensity. The cumulative negative effect value of energy intensity also increased first and then decreased from 2001 to 2020. The maximum cumulative negative effect value in 2016 was -473.0154 million tons. The cumulative negative effect value of energy intensity decreased from 2017 to 2019, which proves that the energy intensity has increased in recent years. In summary, reducing energy consumption per unit output value is the key measure of sustainable emission reduction. Therefore, we must attach great importance to the increase in energy intensity.

4.2.3. Analysis of Energy Carbon Emission Intensity Effect. Energy carbon emission intensity is the second factor for the mining industry to reduce carbon emission. The cumulative negative effect of energy carbon emission intensity has steadily increased from -0.535 tons in 2001 to -35.4025 million tons in 2009. In the later stage, the cumulative negative effect has decreased slightly, and the cumulative effect will be -25.5046 million tons by 2020 . Generally speaking, the cumulative effect of energy carbon emission is relatively stable. Energy carbon emission intensity is equivalent to carbon emission factor for each specific energy, and the carbon emission factor is usually fixed. Because the energy in this study is divided into four categories for analysis, each type of energy includes many specific energies, such as coal, including raw coal, washed coal, other washed coal, coke, coke oven gas, blast furnace gas, other gas, and other coking products. Therefore, when there is a change in the specific energy in the large category of energy or the improvement of energy development and production technology, it will cause the change in energy carbon emission intensity. Finally, through data research, it is considered that the impact of energy carbon emission intensity on carbon emission is very limited.

4.2.4. Analysis of Energy Structure Effect. The cumulative effect of energy structure has both positive and negative effects on carbon emissions. From 2002 to 2013, it is basically a negative cumulative effect. In 2008 , the maximum negative cumulative effect was -20.5183 million tons. From 2014 to 2020 , the cumulative effect is positive. In 2020, the cumulative effect of energy structure was 21.191 million tons. Overall, the effect of energy structure on carbon emission reduction is unstable, and in particular after 2009, the effect of energy structure leads to an increase in the carbon emission of mining industry. In 2009, the mining industry reduced the consumption of coal and increased the consumption of natural gas. The consumption of petroleum energy changed little, and the consumption of secondary energy increased. In 2020, the proportion of secondary energy consumption was $39.28 \%$, exceeding the sum of coal and petroleum energy consumption, and the carbon emission of secondary energy in 2014 exceeded that of primary energy, as shown in Figures 2 and 4. It can be seen that the current energy consumption structure of the mining industry relying on increasing secondary energy does not reduce carbon emissions, but increases. Therefore, the mining industry needs to improve the current energy consumption structure to reduce carbon emissions.

4.2.5. Analysis of Industrial Structure Effect. The industrial structure is the second factor to promote carbon emission. The cumulative effect of industrial structure has been positive from 2001 to 2020 and shows an increasing trend. The cumulative effect of industrial structure increased from 11.438 million tons in 2001 to 36.2822 million tons in 2020, as shown in Table 4. In China's mining industry, coal mining and petroleum and gas mining have always accounted for a high proportion, basically reaching more than $70 \%$, but the proportion of other industries has increased in recent ten years, and the carbon emission intensity of other industries is higher than that of the coal industry, as shown in Figure 3, so the industrial structure has always been a factor to promote carbon emission. Because the industrial structure of mining industry is greatly affected by the national macroeconomic environment, the space for industrial structure adjustment is very limited. 
TABLE 4: Cumulative effects of various factors of carbon emission from 2001 to $2020\left(10^{4} \mathrm{t}\right)$.

\begin{tabular}{|c|c|c|c|c|c|c|}
\hline Year & $\Delta \mathrm{C}$ & $\Delta C_{\mathrm{T}}$ & $\Delta C_{\mathrm{S}}$ & $\Delta C_{\mathrm{V}}$ & $\Delta C_{\mathrm{M}}$ & $\Delta C_{\mathrm{G}}$ \\
\hline 2001 & 1894.90 & -53.50 & 214.56 & 1360.03 & 1143.80 & -1839.73 \\
\hline 2002 & 2362.42 & -1538.54 & -123.96 & 1008.39 & 1418.05 & 528.74 \\
\hline 2003 & 5395.56 & -1016.03 & -553.97 & 273.32 & 1409.64 & 4212.86 \\
\hline 2004 & 6545.83 & -1306.46 & 587.91 & -4862.11 & 2047.56 & 9009.18 \\
\hline 2005 & 7416.49 & -1475.10 & 570.21 & -9325.12 & 2143.20 & 14433.56 \\
\hline 2006 & 6267.01 & -1636.91 & -691.33 & -13947.64 & 2412.60 & 19060.55 \\
\hline 2007 & 7330.83 & -2491.21 & -1056.17 & -17187.51 & 2729.24 & 24266.74 \\
\hline 2008 & 8089.71 & -3216.04 & -2051.83 & -20420.92 & 2990.66 & 29718.09 \\
\hline 2009 & 12101.08 & -3540.25 & -1993.89 & -20795.49 & 2978.55 & 34382.41 \\
\hline 2010 & 13961.45 & -3120.39 & -1352.40 & -26136.44 & 2974.46 & 40526.46 \\
\hline 2011 & 17578.96 & -2032.31 & -242.41 & -29681.80 & 2901.93 & 45563.80 \\
\hline 2012 & 19318.37 & -3173.57 & -817.85 & -29361.51 & 2315.31 & 49286.26 \\
\hline 2013 & 19332.06 & -3516.36 & -211.34 & -33714.19 & 2082.12 & 53622.09 \\
\hline 2014 & 12398.97 & -2729.18 & 1110.72 & -44320.16 & 2085.42 & 55182.42 \\
\hline 2015 & 11670.68 & -3417.40 & 673.04 & -43971.69 & 2710.98 & 54606.01 \\
\hline 2016 & 8639.10 & -2734.78 & 1631.70 & -47301.54 & 3007.29 & 52966.69 \\
\hline 2017 & 10336.74 & -2691.85 & 1741.70 & -38606.38 & 3464.91 & 45358.63 \\
\hline 2018 & 10312.52 & -2076.30 & 1401.81 & -34234.87 & 3170.39 & 40981.75 \\
\hline 2019 & 10889.97 & -2550.45 & 1650.76 & -31033.21 & 3560.82 & 38192.31 \\
\hline 2020 & 10437.06 & -2550.46 & 2119.10 & -31650.76 & 3628.22 & 37821.21 \\
\hline
\end{tabular}

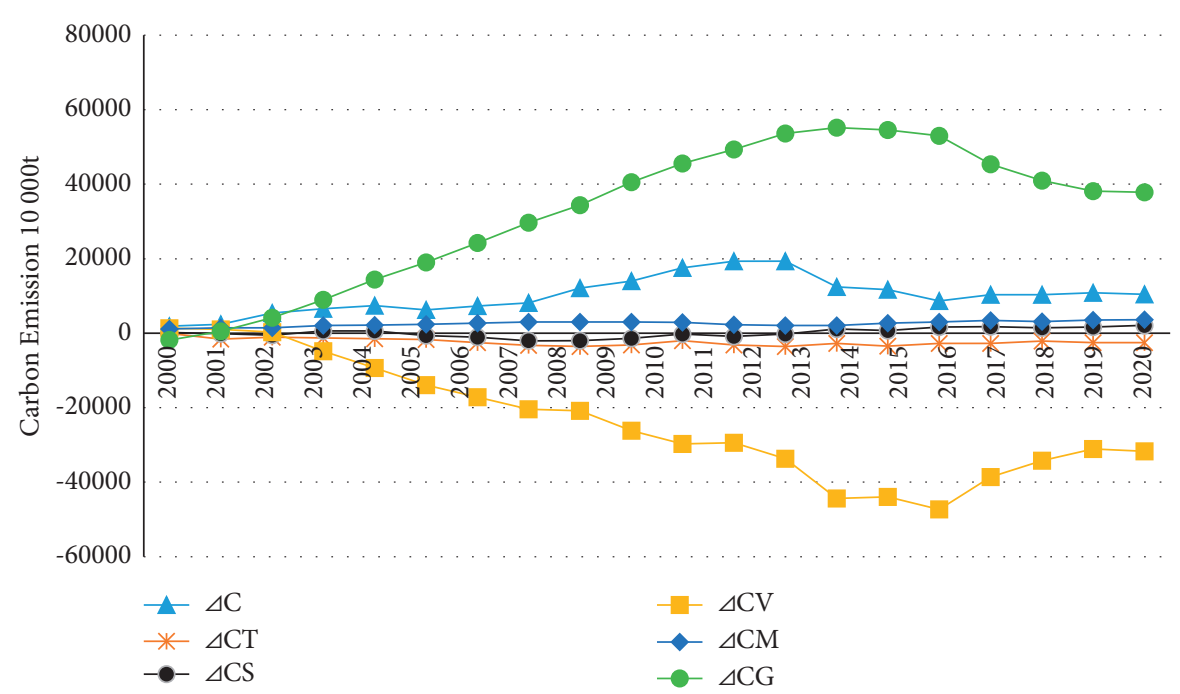

FIgURE 6: Cumulative effect of various factors of carbon emission from 2001 to 2020.

\section{Conclusion}

First, from 2000 to 2020, the carbon emissions and carbon emission intensity of energy consumption in China's mining industry increased first, then decreased, and then rebounded slightly. The carbon emission intensity of mining industry has been stable at 2 tons/ 10000 yuan in recent three years. In recent three years, the carbon emission intensity from high to low is nonmetallic industry, nonferrous metal industry, petroleum and gas industry, ferrous metal industry, and coal mining industry, of which the coal mining industry decreases the fastest and the carbon emission intensity of the nonmetallic industry increases instead of decreasing.

Mining and washing of coal industry is the largest contributor to carbon emission of mining industry, followed by oil and gas mining industry, nonmetallic industry is the third, ferrous metal industry is the fourth, and nonferrous metal industry is the last. From the perspective of energy structure, the carbon emission of secondary energy has always been the highest, and its carbon emission exceeded the total of primary energy in 2014. Coal consumption ranked second in carbon emissions, but it has decreased significantly since 2014. In recent three years, the carbon emission of natural gas consumption ranked third, and the emission of petroleum consumption was the least.

Second, the increase in output value is the largest contributor to the increase in carbon emissions. The cumulative effect of output value in 2014 was 551.8242 million tons, which is the highest value in the history, and the annual effect of output value from 2015 to 2020 was negative. These data show that the main means of reducing carbon emissions in China's mining industry in recent years are to reduce output value. 
Third, energy intensity is the biggest driving force for carbon emission reduction. The maximum cumulative negative effect of energy intensity in 2016 was -473.0154 million tons, and the annual effect from 2017 to 2019 was positive, as shown in Table 3. This shows that the increase in energy consumption per unit output value in recent years is very unfavorable to carbon emission reduction. Reducing energy consumption per unit output value is not only an important factor in reducing carbon emissions, but also an important path for low-carbon development of mining industry.

Fourth, the effect of energy structure on carbon emission is unstable. The cumulative effect in 2020 is 21.191 million tons, indicating that the energy structure of mining industry is not conducive to carbon emission reduction in recent years; that is, increasing secondary energy consumption does not reduce carbon emission.

Fifth, energy carbon emission intensity and industrial structure have limited effect on carbon emission of mining industry, because the space for adjustment of these two factors is very limited, and their impact on carbon emission is limited.

\section{Conflicts of Interest}

The authors declare that they have no conflicts of interest.

\section{Acknowledgments}

This work was financially supported by the 13th Five-Year Plan of Educational Science in Shandong Province (Grant No. 2020ZC225) and the Shandong Social Science Planning and Research Project (Grant Nos. 17CJJJ09 and 18CJJJ25).

\section{References}

[1] World Bank, "Mineral Products for Climate Action: mineral Consumption Intensity of Clean Energy Transformation," World Bank, Washington, D.C., USA, 2020.

[2] Geological Publishing House, "Ministry of natural resources," China mineral Resources Report, pp. 15-20, Geological Publishing House, Beijing, China, 2020.

[3] First Finance and Economics, "The path, opportunities and challenges of china's “carbon Neutrality" Goal in 2060," 2020, https://www.yicai.com/news/100843313.html.

[4] H. Qiang and B. Gao, "Options for Sustainable Development of Mining Industry under the Background of Carbon Neutrality," Natural Resources Economics of China, vol. 4, pp. 4-11, 2021, (in Chinese).

[5] Q. Wu, "Research on the Total Factor Productivity of Mining Industry and its Influencing Factors Considering Carbon Emissions," pp. 40-45, China University of Geosciences, Beijing, China, 2017, Dissertation.

[6] K. Dong, R. Sun, G. Hochman, and H. Li, "Energy intensity and energy conservation potential in China: a regional comparison perspective," Energy, vol. 155, pp. 782-795, 2018.

[7] Z. Wen, Y. Wang, H. Li, Y. Tao, and D. De Clercq, "Quantitative analysis of the precise energy conservation and emission reduction path in China's iron and steel industry," Journal of Environmental Management, vol. 246, pp. 717-729, 2019.
[8] M. Chang, J. Zheng, Y. Inoue, X. Tian, Q. Chen, and T. Gan, "Comparative analysis on the socioeconomic drivers of industrial air-pollutant emissions between Japan and China: insights for the further-abatement period based on the LMDI method," Journal of Cleaner Production, vol. 189, pp. 240-250, 2018.

[9] Y. Kaya, Impact of Carbon Dioxide Emission on GNP Growth: Lnterpretation of Proposed Scenarios. Presentation to the Energy and Lndustry Subgroup, Response Strategies Working Group, IPCC, Paris, France, 1989.

[10] Z. Liao, "Content analysis of China's environmental policy instruments on promoting firms' environmental innovation," Environmental Science \& Policy, vol. 88, pp. 46-51, 2018.

[11] B. Ang, F. Zhang, and K. Choi, "Factorizing changes in energy and environmental indicators through decomposition," Energy, vol. 23, no. 6, pp. 489-495, 1998.

[12] B. W. Ang and F. L. Liu, "A new energy decomposition method: perfect in decomposition and consistent in aggregation," Energy, vol. 26, no. 6, pp. 537-548, 2001.

[13] B. W. Ang, "Decomposition analysis for policymaking in energy:which is the preferred method," Energy Policy, vol. 32, no. 9, pp. 1131-1139, 2004.

[14] L. Shen and Y. Sun, "Review on carbon emissions, energy consumption and low-carbon economy in China from a perspective of global climate change," Journal of Geographical Sciences, vol. 26, no. 7, pp. 855-870, 2016.

[15] C. Guo, "Decomposition of China's carbon emissions: based on LMDl method," China Population, Resources and Environment, vol. 20, no. 12, pp. 4-9, 2010, (in Chinese).

[16] S. Xie, L. Wang, and Z. Shao, "Analysis on industrial difference and motivation factor of carbon emission intensity," Research of Environmental Sciences, vol. 26, no. 11, pp. 1252-1258, 2013.

[17] K. Li and B. Lin, "How to promote energy efficiency through technological progress in China," Energy, vol. 143, pp. 812821, 2018.

[18] Y. Liu, B. Yan, and Y. Zhou, "Urbanization, economic growth, and carbon dioxide emissions in China: a panel cointegration and causality analysis," Journal of Geographical Sciences, vol. 26, no. 2, pp. 131-152, 2016.

[19] L. Zhiguo and L. Zongzhi, "Empirical analysis on decomposition of carbon emission factors of agricultural energy consumption in China: based on lmdl model," Agricultural technology and economy, no. 10, pp. 66-72, 2010.

[20] T. Fan, R. Luo, and F. fan, "Study on Influencing Factors of carbon dioxide emission from China's chemical industry," China soft science, vol. 27, no. 3, pp. 166-174, 2013, (in Chinese).

[21] Y. Hu and D. Chu, "Decoupling analysis of CO2 emission, output value and energy consumption of China's construction industry," China's Population, Resources and Environment, vol. 25, no. 8, pp. 50-57, 2015, (in Chinese).

[22] P. Yin, P. Duan, and C. Chen, "Study on carbon emission pattern of transportation and its relationship with economic growth in China," Resources and Environment in Arid Areas, vol. 30, no. 5, pp. 7-12, 2016.

[23] L. Jia, X. Chen, and Z. Zhang, "Carbon emission characteristics and factor decomposition of China's tourism," Resources and Industry, vol. 9, no. 3, pp. 67-76, 2017.

[24] Y. Fang, "Research on influencing factors of carbon emissions in China's coal production areas-based on the improved LMDI model," Coal Economic Research, vol. 40, no. 12, pp. $40-45,2020$. 
[25] Ipcc, "IPCC Guidelines for National Greenhouse Gas Inventories," Energy, vol. 2, 2006.

[26] NDRC, Guidelines for Accounting Methods and Reporting of Greenhouse Gas Emissions of Enterprises, NDRC, Beijing, China, (in Chinese), 2021.

[27] NBSC, Provincial Greenhouse Gas Inventory Preparation Guidelines (Trial), NDRC, Beijing, China, (in Chinese), 2011.

[28] NDRC, China Energy Statistical Yearbook(2000- 2020), China Statistics Press, Beijing, China, (in Chinese), 2000.

[29] NBSC, China Statistical Yearbook(2000-2020), China Statistics Press, Beijing, China, (in Chinese), 2000.

[30] NDRC, "National Climate Change Plan (2014-2020)," 2014, http://www.scio.gov.cn .(in Chinese). 